\title{
Section introduction Psychosocial controversies in breast cancer
} Lesley Fallowfield

CRUK Sussex Psychosocial Oncology Group, Brighton \& Sussex Medical School, University of Sussex, Falmer, Brighton, BN1 9QG, UK

Corresponding author: Lesley Fallowfield, L.J.Fallowfield@sussex.ac.uk

Published: 20 December 2007

This article is online at http://breast-cancer-research.com/content/9/S2/S2 (c) 2007 BioMed Central Ltd

The many exciting advances in breast cancer treatment made over the past decade mean that more women are now cured of their disease or are living longer with a better quality of life (QoL). These research-driven improvements in care have taken place against a backdrop of many other societal and cultural changes, which in themselves are now influencing the content and conduct of both research and clinical practice. For some time now medical care has had a more patientcentred focus, with patients expecting to be given more autonomy as a partner in determining their own treatment rather than merely a passive recipient of paternalistic care. Patients expect to be treated with dignity and respect, to be given clear information about their disease and invited to choose between the possible therapeutic options. To be able to deliver on these expectations, many health care professionals need better communication skills training. Attitudinal shifts are also required, which can be difficult for some who are educated within different cultures and more hierarchically based systems.

Breast cancer advocacy groups worldwide have put breast cancer very firmly on the political agenda. Their lobbying has undoubtedly led to better quality breast cancer care, which is a model envied by those working in other tumour sites. Some providers of cancer services feel that breast cancer patients, because of their high profile, relentless activity and celebrity supporters, may be getting more of the health care budget than is fair.

Patient representatives now play a formal role on most clinical trial steering committees. In the past their role was often tolerated rather than welcomed, but some have earned their place at the table by making valuable contributions to discussions not only about patient information sheets but also about the likely feasibility that a trial and its subprotocols will be acceptable to other patients. As these individuals and the groups supporting them have become more powerful, they have also demanded a greater say in the type of research that is conducted. Because it is often charitable groups that raise much of the money to pay for research, it seems only
Breast Cancer Research 2007, 9(Suppl 2):S2 (doi:10.1186/bcr1800)

reasonable that they should have a say in what research is done; this is leading to tensions, particularly among basic, blue skies researchers who feel that the complexity and potential utility of their type of work is unfathomable and unattractive to laypeople compared with, say, supportive care research looking at pain relief or massage therapy.

Although new systemic treatments for breast cancer have improved the outlook for patients in terms of disease-free and overall survival, many women will experience side effects that are often underestimated and consequently under-treated. In adjuvant treatment for early breast cancer, many women who have already successfully been treated with surgery and radiotherapy have chemotherapy or hormone therapy, from which they will derive no further benefit and merely iatrogenic harms. This can affect adherence and, if side effects are not dealt with adequately, push patients into the arms of alternative and complementary therapists. Although there is a literature accumulating showing measurable benefits in terms of reduction in stress, pain and vasomotor complaints from such things as aromatherapy, therapeutic massage and acupuncture, other areas such as homeopathy have no evidence base and arouse polarized and passionate debate. There are major concerns about the volume of nonprescription drugs that patients are taking, which at the very least damage their bank balances but at worst seriously interfere with their anticancer treatments. Unless side effects are measured and monitored adequately within clinics, it will not be possible to collect data demonstrating the non-lifethreatening but QoL-threatening side effects that compromise adherence or that send women running to complementary therapists. This is bad enough in an adjuvant setting, but it is not acceptable in advanced metastatic disease, where preserving QoL may be the only criterion of benefit. We have excellent psychometric tools with which to measure QoL, and evidence is accumulating that they have predictive value that could help to guide management. It is rare outside a clinical trial to see formal assessment of QoL. In contrast, despite their dubious utility, much energy is invested in measuring tumour markers. 
Table 1

\section{Audience responses to questions before the talks and after the discussion period}

\begin{tabular}{lccc}
\hline Before/after discussion & Yes & No & Unsure \\
\hline $\begin{array}{l}\text { Is patient representation on trial steering committees helpful? } \\
\text { Before }\end{array}$ & 53 & 16 & 32 \\
After & 44 & 38 & 18 \\
Should patients be involved in clinical trial design? & 38 & 39 & 23 \\
Before & 32 & 56 & 11 \\
After & 63 & 24 & 13 \\
Do patient advocacy groups help speed up introduction of new drugs in the clinic? & 8
\end{tabular}

Are patient advocacy groups responsible for distorting cancer budget in favour of breast over other tumours?

$\begin{array}{llll}\text { Before } & 79 & 11 & 10 \\ \text { After } & 66 & 30 & 5\end{array}$

Should formal QoL play a major role in the management of MBC patients?

$\begin{array}{lccc}\text { Before } & 73 & 14 & 14 \\ \text { After } & 90 & 8 & 2\end{array}$

Are patient self-reports in QoL questionnaires more accurate than clinicians' records of side effects?

$\begin{array}{llcr}\text { Before } & 50 & 25 & 25 \\ \text { After } & 80 & 8 & 13\end{array}$

When making decisions about local surgical therapy women prefer.$^{\text {a }}$

$\begin{array}{llll}\text { Before } & 10 \text { (Dr to choose) } & 83 \text { (joint decision) } & 7 \text { (patient choice) } \\ \text { After } & 5 \text { (Dr to choose) } & 81 \text { (joint decision) } & 14 \text { (patient choice) }\end{array}$

Should breast cancer patients be encouraged to try complementary therapy?

$\begin{array}{llll}\text { Before } & 23 & 48 & 29 \\ \text { After } & 31 & 38 & 31\end{array}$

Do nonprescription drugs help the symptoms and side effects?

$\begin{array}{llll}\text { Before } & 39 & 20 & 41 \\ \text { After } & 38 & 23 & 39\end{array}$

aFor this question, the options were 'Dr to choose', 'joint decision' and 'patient choice'. MBC, metastatic breast cancer; QoL, quality of life.

The following eight papers establish the case for and against some of the issues raised, including patient representation, patient advocacy, QoL, and decision making about surgical therapy and complementary therapy. The invited audience were asked to vote on the questions or statements shown below before the talks and then after a discussion period. The results are summarized in Table 1.

Regarding patient representation, after the talks it was agreed that it was really impossible to find a 'generic' patient to represent all. There was a shift toward the view that patients' presence was not necessarily always helpful but recognition of political correctness would make change impossible, especially in the USA. With respect to whether patients should be involved in clinical trial design, it was clear that patient priorities would be very different and likely that much basic science would never be supported. Regarding advocacy groups, the audience were all working in breast cancer and recognized that patient advocacy groups were undoubtedly very powerful in getting access to new drugs. It was also recognized that it would always be impossible to find activists as powerful for other tumours, such as lung or colorectal, and so breast is unlikely to be a 'model' for these sites.

Sufficient evidence was provided demonstrating that patient self-reports are more accurate than data from physician completed case report forms (CRFs). QoL questionnaires are 
used routinely in clinical trials. It is therefore unclear why they are not used to guide management of metastatic breast cancer because tumour markers are not always feasible, available, or helpful. Technology (touch screens) exist to help administration of questionnaires.

Data were presented showing that there were discrepancies between patient's and doctors' views as to how decisions are made. Some of the audience were persuaded that patient choice was something many but not all women wanted.

The session on complementary therapy produced the liveliest debate. Semantics proved important because many things are included under the umbrella of complementary and alternative medicine (CAM). There were many assertions made for CAM benefits but no really hard data were offered in support during the session. Concerns were raised about endorsement by celebrities and sportsmen. Finally, there are differences in criteria for acceptance of treatments: conventional drugs go through rigorous testing and their labelling is regulated, but this is not the case for CAM.
On the issue of symptoms and side effects, despite few data demonstrating efficacy beyond a placebo effect, many patients take nonprescription drugs that could seriously interfere with breast cancer treatments. Better communication is needed about side effects, as is more research to ameliorate unpleasant symptoms associated with breast cancer treatment.

There are many psychosocial and ethical controversies in the field of breast cancer. These are rarely discussed thoroughly by multidisciplinary groups of clinicians and scientists together. Such important topics are usually relegated to small parallel symposia attended by social scientists. The issues debated affect all - patients, clinicians and scientists - and they are worthy of more discussion.

\section{Acknowledgement}

This article has been published as part of Breast Cancer Research Volume 9 Supplement 2, 2007: Controversies in Breast Cancer. The full contents of the supplement are available online at http://breastcancer-research.com/supplements/9/S2. 